\title{
Medication Use Patterns among Urban Youth Participating in School-Based Asthma Education
}

\author{
Bina Patel Shrimali, Amira Hasenbush, Adam Davis, \\ Ira Tager, and Sheryl Magzamen
}

\begin{abstract}
Although pharmaceutical management is an integral part of asthma control, few community-based analyses have focused on this aspect of disease management. The primary goal of this analysis was to assess whether participation in the school-based Kickin' Asthma program improved appropriate asthma medication use among middle school students. A secondary goal was to determine whether improvements in medication use were associated with subsequent improvements in asthma-related symptoms among participating students. Students completed an in-class case-identification questionnaire to determine asthma status. Eligible students were invited to enroll in a school-based asthma curriculum delivered over four sessions by an asthma health educator. Students completed a pre-survey and a 3-month follow-up post-survey that compared symptom frequency and medication use. From 2004 to 2007, 579 participating students completed pre- and post-surveys. Program participation resulted in improvements in appropriate use across all three medication use categories: $20.0 \%$ of students initiated appropriate reliever use when "feeling symptoms" ( $p<0.001), 41.6 \%$ of students reporting inappropriate medication use "before exercise" initiated reliever use $(p<0.001)$, and $26.5 \%$ of students reporting inappropriate medication use when "feeling fine" initiated controller use $(p<0.02)$. More than half $(61.6 \%)$ of participants reported fewer symptoms at post-survey. Symptom reduction was not positively associated with improvements in medication use in unadjusted and adjusted analysis, controlling for sex, asthma symptom classification, class attendance, season, and length of follow-up. Participation in a school-based asthma education program significantly improved reliever medication use for symptom relief and prior-to-exercise and controller medication use for maintenance. However, given that symptom reduction was not positively associated with improvement in medication use, pharmaceutical education must be just one part of a comprehensive asthma management agenda that addresses the multifactorial nature of asthma-related morbidity.
\end{abstract}

KEYWORDS Child and adolescent health, Chronic disease, Evaluation, Asthma, Medication use, Reliever, Controller, Exercise-induced

\section{INTRODUCTION}

Inappropriate asthma medication use can increase asthma-related morbidity. National guidelines recommend limited use of short-acting bronchodilator (hereafter referred to as reliever) medications to mitigate symptoms during exacerbations for all children with asthma and before physical activity for those who experience

Patel Shrimali, Tager, and Magzamen are with the Division of Epidemiology, School of Public Health, University of California, Berkeley, CA, USA; Patel Shrimali, Hasenbush, and Davis are with the American Lung Association of California, Emeryville, CA, USA.

Correspondence: Bina Patel Shrimali, Alameda County Public Health Department, Oakland, CA, USA. (E-mail: bina513@gmail.com) 
exercise-induced symptoms. Daily use of anti-inflammatory (hereafter referred to as controller) medications is recommended to control inflammation and prevent asthma exacerbations for children with persistent asthma. ${ }^{1}$

A survey of families of inner-city children with asthma found that over $50 \%$ of children assumed responsibility for their own medication by age 9 with the percentage increasing as children entered adolescence. ${ }^{2}$ Increased personal responsibility for disease management makes adolescents with asthma particularly vulnerable to poor asthma control. ${ }^{3}$ Barriers to medication use reported by adolescents with asthma included bad taste, difficulty with administration, cost, inconvenience, social undesirability, and doubt regarding its necessity. ${ }^{3}$ Several studies have identified the need for clear messages regarding optimal medication use ${ }^{3-6}$ as adolescents often do not understand the preventive role of controller medications or are confused about the purpose of various asthma medications. ${ }^{3}$ These misunderstandings are associated with decreased appropriate medication administration. ${ }^{6}$

Schools are logical sites for the implementation of asthma education programs. ${ }^{7,8}$ Asthma education for children who face increasing responsibility for their asthma medication might improve health outcomes and reduce absenteeism. ${ }^{9}$ However, most published research focuses on asthma education in elementary schools, ${ }^{10-17}$ with few interventions designed for middle school students. ${ }^{3,18}$ Two studies of school-based asthma education programs for adolescents included activities addressing asthma medication use, ${ }^{11,12}$ but neither study reported changes in appropriate medication use as a result of program participation. Of the two crosssectional studies of medication use by students in public schools, one reported that $80 \%$ of adolescents with asthma used inhalers but did not differentiate between controller and reliever medications, ${ }^{18}$ and the other reported low use of controller medication by elementary school students but did not assess appropriate use. ${ }^{2}$

To address the specific asthma-related needs of the middle school population, Oakland Kicks Asthma, a large community-based intervention in Oakland, California, developed an asthma management education program for students in the Oakland Unified School District (OUSD), a diverse, predominantly low-income urban school district with high asthma prevalence. ${ }^{719}$ Known as Kickin' Asthma, this curriculum for sixth-grade students with asthma teaches management strategies with an emphasis on appropriate medication use. The primary goals of this analysis are (1) to assess whether participation in this program improved appropriate asthma medication use and (2) to determine whether improvements in medication use were associated with subsequent improvements in asthma-related symptoms among participating students.

\section{METHODS}

Case Identification and Recruitment. The methods for asthma case identification and recruitment have been published previously. ${ }^{7,19,20}$ Oakland Kicks Asthma staff administered a 14-item questionnaire based on the International Study of Asthma and Allergy in Childhood (ISAAC) to all participating sixth-grade students in noncharter public schools in the OUSD. ${ }^{21}$ Prior to administration, parents received a letter that described the project; they were able to decline participation, but active parental consent was not required to complete the questionnaire. Students were also able to decline participation at the time of administration. Students reporting a medical diagnosis of asthma and current symptoms were classified into high or low symptom asthma categories (classification algorithm available on request). All 
students classified as having high- or low-symptom asthma were invited to participate in Kickin' Asthma. 7,19,20 Students with asthma symptoms who were not identified through the questionnaire were referred to the program by teachers or other school staff.

Kickin' Asthma Intervention. As described elsewhere, ${ }^{7,19}$ the Kickin' Asthma intervention enrolled students in four weekly sessions taught during lunch by American Lung Association staff and OUSD nurses. The curriculum emphasized optimal medication use, including differences between controller and reliever medications; appropriate timing for medication use and effective methods for selfadministration; and solutions to common student-identified barriers to appropriate use.

Data Collection. Students completed an 11-question survey of symptom frequency, healthcare utilization, and self-management practices, once before participation in the intervention and again 3 months after the final class. Using color photographs of common asthma medications, instructors asked additional questions to identify the specific medications the students took when "having symptoms" (to assess appropriate reliever use), "before exercise" (to assess appropriate reliever use prior, to physical activity), and "feeling fine" (to assess appropriate controller use). Data on the frequency of medication use were unavailable. The University of California, Berkeley Committee for the Protection of Human Subjects approved all data collection and intervention activities.

Data Analysis. Data from the 2004-2005, 2005-2006, and 2006-2007 school years were combined for the analysis. Appropriate medication use was assessed under the three situations described above: when "feeling symptoms," "before exercise," and when "feeling fine," (referred to hereafter as "medication use categories"). Appropriate use was defined as reliever use when "feeling symptoms" and "before exercise" and controller use when "feeling fine." Students' responses to both the pre- and post-surveys were analyzed to determine (1) changes in appropriate use for each medication use category and (2) associations between changes in medication use and asthma symptoms.

Changes from pre- to post-survey in appropriate use for the three medication use categories were assessed using McNemar's test. Because guidelines recommend the prescription of reliever medication for all children with asthma, all students were included in the analysis for medication use when "feeling symptoms." Students who reported any medication use before exercise on the pre- or post-survey were presumed to be in need of pre-exercise medication and were included in the analysis of appropriate use of reliever medication before exercise. Similarly for the medication use category "feeling fine," analysis was limited to students who reported taking a controller medication at any time, which limited the analysis to those students for whom a controller had been prescribed by a health care provider and who presumably had persistent asthma.

A Chi-square test was performed to assess the association of overall change in medication use with a reduction in asthma symptoms from pre- to post-survey. For each of the three medication use categories, students received a score of 1 upon initiation of appropriate medication use, -1 upon initiation of inappropriate medication use, and 0 when medication use did not change (i.e., the student continued appropriate or inappropriate use) from pre- to post-survey. The sum of these three scores was used to assign students an overall medication use score 
indicating (1) improved (combined score $>0$ ), (2) worsened (combined score $<0$ ), and (3) no change in medication use (combined score $=0$ ). Change in asthma symptoms was assessed for each of the following: (1) daytime symptoms in the past 4 weeks, (2) daytime symptoms in the past 3 months, (3) nighttime symptoms in the past 4 weeks, (4) sleep disruptions in the past 4 weeks, (5) difficulty playing a sport or exercising in the past 4 weeks, (6) missed school days in the past 4 weeks, and (7) emergency department visits for asthma in the past 3 months. These differences were summed to create an overall symptom score; students with a sum greater than 0 were considered to have improved asthma symptoms. Students missing data to assess symptom change were excluded from this analysis $(n=1)$.

Separate logistic regression analyses were implemented to assess the association between change in each medication use category and change in symptom frequency. The outcome for the medication use categories "feeling symptoms" and "feeling fine" was symptom improvement as defined above. The outcome for the medication use category "before exercise" was reduced frequency of difficulty playing a sport or exercising in the previous 4 weeks. The main predictor of interest was the change in appropriate medication use from pre- to post-survey (i.e., initiation of appropriate medication use, initiation of inappropriate medication use, and continued inappropriate medication use with reference category continued appropriate medication use). Covariates included in the adjusted analyses were sex, season of class attendance, number of classes attended, length between pre- and post-surveys, and high or low asthma symptom classification based on the case identification questionnaire. Students missing data on sex $(n=2)$, class attendance $(n=17)$, or symptom change $(n=17)$ were excluded from these analyses. All analyses were performed using SAS version 9.1 (Cary, NC).

\section{RESULTS}

Between 2004 and 2007 the case identification questionnaire was completed by 6,819 students $17.4 \%(n=1,170)$ were identified as having high- or low-symptom asthma and were invited to participate in the program (Figure 1). Of the eligible students, 1,077 enrolled in the program and completed the pre-survey; 579 students $(53.8 \%)$ also completed the post-survey. Students who completed both the pre- and post-survey differed from students completing the pre-survey only in that they were more likely to have high symptom asthma as determined by the case identification questionnaire (difference $-11.2 \%$; $95 \%$ confidence interval $(\mathrm{CI})-16.4 \%,-6.0 \%$ ), to attend classes in the fall or winter, and to complete all four classes (Table 1).

There were no significant differences between students who completed and did not complete the post-survey in the number of daytime or nighttime symptoms, school absences, sleep disturbances, or emergency department visits reported on the pre-survey. The odds of post-test completion increased with each additional Kickin' Asthma class attended (odds ratio (OR) 2.38; 95\% CI 2.09, 2.73) and decreased with each additional day of pre-test exercise symptoms (OR 0.93 ; 95\% CI 0.88 , 0.99). The odds of post-survey completion were higher for those using medication appropriately on the pre-survey when "feeling symptoms" (OR 1.34; 95\% CI 1.08, 1.75 ) and "before exercise" (OR 1.34; 95\% CI 1.03, 1.74), but not significantly for those using medication appropriately when "feeling fine" (OR 1.25; 95\% CI 0.94, 1.68; data not shown). 


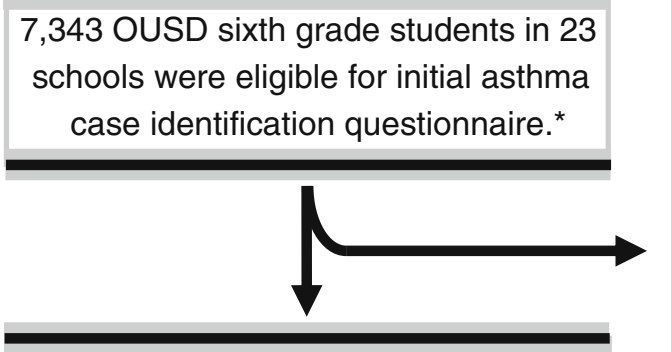

6,819 students completed case identification questionnaire.

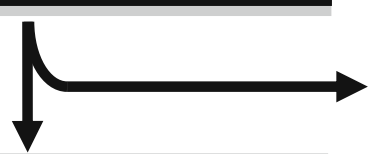

1,170 students (17.2\%) with an asthma diagnosis and current symptoms were invited to attend Kickin' Asthma.

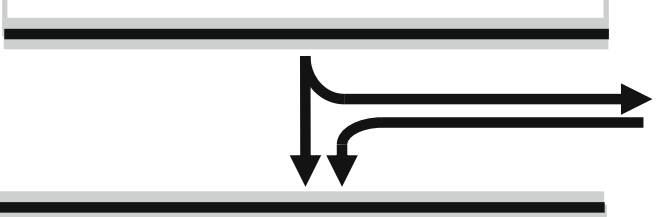

1,077 students attended at least one class and took the pre-survey.

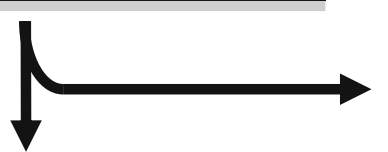

579 students $(53.8 \%)$ took the postsurvey.

FIGURE 1. Kickin' Asthma participants, Oakland Unified School District, school years 2004-2005, 2005-2006, and 2006-2007. *Case-identification questionnaire has been previously described. ${ }^{8,20,21}$

\section{Medication Use Patterns}

Among students who completed both the pre- and post-survey, $64.6 \%$ of students reported appropriate medication use when "feeling symptoms," $34.4 \%$ "before exercise," and $24.8 \%$ when "feeling fine," on the pre-survey (Table 2). On the postsurvey, the proportion of students using medication appropriately for each category of medication use increased. Students reporting no medication use declined for each category. There was significant improvement in medication use when "feeling symptoms," with $20.0 \%$ initiating appropriate medication use $(p<0.01$; Table 3$)$. The majority $(52.4 \%)$ of students continued to use reliever medication appropriately when "feeling symptoms" from the pre- to post-survey. The greatest improvement in medication use behavior occurred for students taking medications "before exercise," 
TABLE 1 Characteristics of Kickin' Asthma participants by level of participation

\begin{tabular}{|c|c|c|c|}
\hline Characteristic & $\begin{array}{l}\text { Completed } \\
\text { pre-survey only } \\
(\% ; n=498)\end{array}$ & $\begin{array}{l}\text { Completed } \\
\text { pre- and post-survey } \\
(\% ; n=579)\end{array}$ & Difference (\%; 95\% Cl) \\
\hline \multicolumn{4}{|l|}{$\operatorname{Sex}^{\mathrm{a}}$} \\
\hline Male & 53.6 & 51.8 & $1.8(-4.3,7.9)$ \\
\hline \multicolumn{4}{|l|}{ Asthma symptom classification ${ }^{b}$} \\
\hline High symptom asthma & 69.1 & 80.3 & $-11.2(-16.4,-6.0)$ \\
\hline Low symptom asthma & 14.9 & 10.7 & $4.2(0.1,8.2)$ \\
\hline Possible asthma & 1.4 & 1.4 & $0.0(-1.4,1.4)$ \\
\hline Inactive asthma & 3.8 & 3.1 & $0.7(-1.5,2.9)$ \\
\hline Unknown classification & 10.8 & 4.5 & $6.4(3.1,9.6)$ \\
\hline \multicolumn{4}{|l|}{ Class attendance $^{\mathrm{a}}$} \\
\hline Attended class 1 & 83.5 & 87.1 & $-3.5(-7.9,0.8)$ \\
\hline Attended class 2 & 67.5 & 89.5 & $-22.0(-26.9,-17.1)$ \\
\hline Attended class 3 & 57.8 & 83.4 & $-25.6(-31.2,-20.1)$ \\
\hline Attended class 4 & 52.2 & 83.4 & $-31.1(-36.8,-25.5)$ \\
\hline \multicolumn{4}{|l|}{ Season of class participation } \\
\hline Fall (September to November) & 11.7 & 19.5 & $-7.9(-12.2,-3.6)$ \\
\hline Winter (December to February) & 50.6 & 58.7 & $-8.1(-14.1,-2.2)$ \\
\hline Spring (March to June) & 37.8 & 21.8 & $16.0(10.6,21.4)$ \\
\hline
\end{tabular}

${ }^{a}$ Missing values are as follows: sex: pre-survey $n=32$, post-survey, $n=2$; class 1 attendance: pre-survey $n=31$, post-survey $n=0$; class 2 attendance: pre-survey $n=31$, post-survey $n=0$; class 3 attendance: pre-survey $n=67$, post-survey $n=7$; class 4 attendance: pre-survey $n=73$, post-survey $n=20$

${ }^{b}$ Asthma symptom classification was determined by the case identification questionnaire. Students in the "high symptom" and "low symptom" asthma categories were invited to participate in Kickin' Asthma. Students in the "possible," "inactive," and "unknown" classifications were referred to the program through teachers or other school staff

with $41.6 \%$ initiating appropriate medication use $(p<0.001)$. In the category of medication use when "feeling fine," there was also significant improvement, with $26.5 \%$ initiating appropriate use $(p=0.02)$. The largest percentage of students $(33.6 \%)$ reported continuing to take appropriate medication when "feeling fine" from the pre- to post-survey. Sex was not significantly associated with changes in medication use for any medication use category. Combining all three medication use categories, $35.6 \% \quad(n=206)$ of students improved, $44.1 \% \quad(n=255)$ showed no change, and $20.2 \%(n=117)$ worsened in overall medication use.

\section{Associations between Reduced Symptoms and Changes in Medication Use}

The sum of differences in all reported symptoms from pre- to post-survey indicated that $61.5 \%$ of students $(n=356)$ reported symptom improvement. Symptom improvement was not significantly associated with overall medication use score $\left(\chi_{(2)}^{2}=1.53, p=0.47\right.$; Table 4$)$.

In the adjusted logistic regression analysis for "feeling symptoms," students who had any change in their medication use (i.e., initiated appropriate or inappropriate use) when "feeling symptoms" were significantly less likely to have improved asthma symptoms compared to the reference group (continued appropriate use; $n=529$; OR $(95 \% \mathrm{CI})$ for initiated appropriate use: $0.58(0.35,0.88)$; for initiated inappropriate 
TABLE 2 Students' self-reported medication use on pre- and post-survey by medication use category

\begin{tabular}{|c|c|c|}
\hline & Pre-test (\%) & Post-test (\%) \\
\hline \multicolumn{3}{|c|}{ Medication reported when "feeling symptoms" $(n=550)$} \\
\hline Reliever $^{\mathrm{a}}$ & 64.6 & 72.4 \\
\hline Controller & 4.5 & 3.1 \\
\hline Both & 7.5 & 6.4 \\
\hline None & 23.5 & 18.2 \\
\hline \multicolumn{3}{|c|}{ Medication reported "before exercise" $(n=559)$} \\
\hline Reliever $^{\mathrm{a}}$ & 34.4 & 49.7 \\
\hline Controller & 2.3 & 1.6 \\
\hline None & 63.3 & 48.7 \\
\hline \multicolumn{3}{|c|}{ Medication reported when "feeling fine" (for maintenance; $n=549$ ) } \\
\hline Reliever & 6.6 & 9.1 \\
\hline Controller $^{\mathrm{a}}$ & 24.8 & 29.3 \\
\hline Both & 5.7 & 3.6 \\
\hline None & 63.0 & 57.9 \\
\hline
\end{tabular}

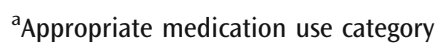

use: $0.50(0.28,0.88))$. No significant association was found for continued inappropriate medication use when "feeling symptoms."

In the adjusted logistic regression analysis for medication use when "feeling fine," students who continued inappropriate medication use were significantly less likely to experience improved asthma symptoms compared to the reference group (continued appropriate use; $n=260$; OR (95\% CI): $0.41(0.20,0.85)$ ). Initiating appropriate or initiating inappropriate medication use when "feeling fine" was not associated with symptom improvement.

TABLE 3 Change in medication use, pre- to post-survey

\begin{tabular}{|c|c|c|c|}
\hline & & \multicolumn{2}{|c|}{ Reported medication use on post-survey } \\
\hline & & Inappropriate & Appropriate \\
\hline \multicolumn{4}{|c|}{ Medication change when "feeling symptoms" $(n=550)^{\mathrm{a}}$} \\
\hline \multirow{2}{*}{$\begin{array}{l}\text { Reported medication use on } \\
\text { pre-survey }\end{array}$} & Inappropriate & $85(15.5 \%)$ & $110(20.0 \%)$ \\
\hline & Appropriate & $67(12.2 \%)$ & $288(52.4 \%)$ \\
\hline McNemar's test & $p<0.01$ & & \\
\hline \multicolumn{4}{|c|}{ Medication change "before exercise" $(n=341)^{\text {b }}$} \\
\hline \multirow{2}{*}{$\begin{array}{l}\text { Reported medication use on } \\
\text { pre-survey }\end{array}$} & Inappropriate & $7(2.1 \%)$ & $142(41.6 \%)$ \\
\hline & Appropriate & $56(16.4 \%)$ & $136(39.9 \%)$ \\
\hline McNemar's test & $p<0.001$ & & \\
\hline \multicolumn{4}{|c|}{ Medication change when "feeling fine" (for maintenance; $n=268)^{c}$} \\
\hline \multirow{3}{*}{$\begin{array}{l}\text { Reported medication use on } \\
\text { pre-survey } \\
\text { McNemar's test }\end{array}$} & Inappropriate & $61(22.8 \%)$ & $71(26.5 \%)$ \\
\hline & Appropriate & $46(17.2 \%)$ & $90(33.6 \%)$ \\
\hline & $p=0.02$ & & \\
\hline
\end{tabular}


TABLE 4 Students with reduced symptoms by overall change in medication use, $n=578$

\begin{tabular}{lccc}
\hline & \multicolumn{2}{l}{ Overall change in medication use } \\
\cline { 2 - 4 } & $\begin{array}{l}\text { Medication use } \\
\text { improved }\end{array}$ & $\begin{array}{l}\text { No change in } \\
\text { medication use }\end{array}$ & $\begin{array}{l}\text { Medication } \\
\text { use worsened }\end{array}$ \\
\cline { 2 - 4 } Reduced symptoms & $n(\%)$ & $n(\%)$ & $n(\%)$ \\
\hline Yes & $126(61.2)$ & $163(63.9)$ & $67(57.3)$ \\
No & $80(38.8)$ & $92(36.1)$ & $50(42.7)$ \\
Total & $206(100)$ & $255(100)$ & $117(100)$ \\
\hline
\end{tabular}

$\chi_{(2)}^{2}=1.53, p=0.47$

In the adjusted logistic regression analysis of medication use "before exercise," students who initiated inappropriate medication use were more likely to experience improved asthma symptoms during exercise compared to the reference group $(n=309$; OR (95\% CI): 2.45 (1.14, 5.25)). Initiating appropriate or continuing inappropriate medication use was not associated with symptom improvement during exercise.

With regard to change in medication use, inappropriate use was inversely associated with improved symptoms except for the "before exercise" medication use category. Initiation of appropriate medication use was inversely associated with symptom improvement for the "feeling symptoms" category. For the "before exercise" model, participation during the spring season compared to the fall was a significant predictor (OR (95\% CI): $2.50(1.16,5.37))$. No other covariates included in any model predicted symptom improvement (regression tables available on request).

\section{DISCUSSION}

Participation in the Kickin' Asthma program resulted in significant improvements in appropriate medication use across all three medication use categories: $20.0 \%$ of students initiated reliever use when "feeling symptoms" (resulting in a total of $72.4 \%$ using medication appropriately in this category post-intervention); $41.6 \%$ of students reporting inappropriate medication use "before exercise" initiated reliever use (resulting in a total of $81.5 \%$ of students using medication appropriately in this category postintervention); and $26.5 \%$ of students reporting inappropriate medication use when "feeling fine" initiated controller use (resulting in a total of $60.1 \%$ using medication appropriately in this category post-intervention). The number of students reporting no medication use also declined for each category.

Results from the analysis indicated that more than half $(61.6 \%)$ of participants experienced improved symptoms; however, this reduction was not linked to improvements in medication use. Proportions of students who experienced fewer symptoms did not differ by change in medication use, and reduction in symptoms was not positively associated with improvement in medication use compared to the reference category for any of the three categories of medication use.

In adjusted analyses of students' medication use "for symptoms" and when "feeling fine," the greatest reduction in symptoms was experienced by students who continued to use medication appropriately, as compared with those who initiated appropriate use, continued inappropriately, or initiated inappropriate use. Students whose medication use worsened "before exercise" had over twice the odds of exercise symptom improvement compared to those whose medication use continued 
correctly. This finding seems counterintuitive but may reflect seasonal and/or behavioral variations in exercise; most students in our analysis attended classes in the fall and may have exercised less frequently and therefore experienced fewer exercise symptoms at the time of follow-up in the winter. It is also possible that cold weather exacerbated asthma morbidity such that students experienced more symptoms despite appropriate medication use. The positive associations between symptom reduction and attending class in spring support this possibility. In addition, information on whether these students required medication use before exercise was unavailable; it is also possible that students whose medication use worsened did not require pre-exercise reliever use.

This analysis has several strengths. To our knowledge, this is the first evaluation of changes in appropriate use of controller and reliever medications among adolescents participating in school-based asthma programs. Color photographs of common asthma medications helped most students identify their medications and explain when they used them, contributing to a more detailed analysis and reduced information bias. In addition, data on medication use in three different categories (i.e., "feeling symptoms," "feeling fine," and "before exercise") enabled us to assess when medication use was most likely to be appropriate and when symptom improvement was associated with change in medication use.

Underuse of controller medication has been widely reported. Only 55\% of children with persistent asthma in a managed care population reported daily use of controller medication. ${ }^{22}$ The level of controller use in our population $(29.3 \%$ of all students who completed the post-survey) is comparable to those found in other urban populations where only a quarter to one-half of children with high-risk asthma reported daily controller use. ${ }^{22}$ The immediate effect of reliever medications may be more evident to students than the prophylactic effects of a slow-acting controller. ${ }^{2}$ The results of this evaluation affirm a challenge pervasive in most chronic disease care: how to motivate changes in behaviors that do not bring immediate, physical relief. ${ }^{23,24}$ In this analysis, performance during exercise may be a powerful motivator among adolescent students, as the largest improvement in medication use was for preventive use in that category.

The analysis also has several limitations. Frequency of medication use, appropriate technique, and changes in the ratio of reliever to controller use were not assessed. Because there were no clinical measures of persistent or exerciseinduced asthma, the analyses for medication use when "feeling fine" or "before exercise" only included students who reported controller or pre-exercise reliever use, respectively, on either the pre- or post-survey. This method may have excluded students who were not prescribed but would have benefitted from these medications. Self-reported data from sixth-grade students may be subject to recall bias and increased reporting of symptoms at post-survey due to heightened awareness prompted by the intervention. Without a control group, the impact of the intervention cannot be distinguished from the natural variation in asthma symptoms. Other factors, including heightened staff and parent awareness, participation in Oakland Kicks Asthma's home-based case management program (in which $15 \%$ of students in this analysis participated), and reduced trigger exposure, may have played a role in changes in medication use behavior and/or symptom reduction. In addition, available information was unable to determine why some students' symptoms improved when they started or continued to use medication inappropriately.

Almost half $(46.2 \%)$ of the students who were invited to Kickin' Asthma did not complete the series or post-survey, indicating the need for more understanding of 
what motivates students to participate in the program. A major concern was that students most in need of education on proper asthma medication use did not complete the program. Odds of post-survey completion were highest for those who entered the program using medication appropriately "for symptoms" or "before exercise." Therefore, students who were taking reliever medication correctly were more likely to complete the program compared to students with inappropriate reliever use patterns. There may be unique, unmeasured features of these students' lives that contributed to both their participation and symptom reduction: easier access to appropriate medication; greater family support for asthma management; and/or more consistency, routine, or organization in their homes and daily routines. This finding may demonstrate the difficulty in reaching and retaining students who have the greatest need for asthma management services.

This analysis highlights the need to understand the barriers to adolescents' appropriate medication use, including those that lie outside of the sphere of an adolescent's influence (e.g., lack of health insurance or transportation for doctor's visits), and to identify those that may be amenable to educational intervention (e.g., misperceptions of asthma as an acute condition or negative beliefs toward pharmaceuticals). Many adolescents attending Oakland public schools face multiple challenges such as language barriers, economic insecurity, violence, unstable family life, lack of health insurance, unhealthy living conditions, and poor air quality, which can increase asthma morbidity and hinder a student's assumption of responsibility for managing his/her asthma. Assessment and prioritization of students' barriers may help to tailor multilevel interventions to simultaneously address barriers that are both outside and within an adolescent's sphere of influence.

School-based health centers, which are currently undergoing expansion in the OUSD, may improve students' access to regular follow-up and appropriate asthma medication. Such structural interventions, in conjunction with educational programs focused on improving self-management, may give students the tools and the ability to control their asthma.

Appropriate medication use is an important educational objective for asthma interventions targeting adolescents, and participation in the Kickin' Asthma curriculum was associated with an improvement in medication use. However, given that symptom reduction was not positively associated with improvement in medication use, pharmaceutical education must be just one part of a comprehensive asthma management agenda that addresses the multifactorial nature of asthmarelated morbidity.

\section{ACKNOWLEDGMENT}

This intervention and its evaluation were partially supported through a cooperative agreement with the Centers for Disease Control and Prevention, US Department of Health and Human Services, under program announcement 03030. The authors would like to thank Beth Macdonald, the staff of the American Lung Association, and the students and staff of the Oakland Unified School District.

OPEN ACCESS This article is distributed under the terms of the Creative Commons Attribution Noncommercial License which permits any noncommercial use, distribution, and reproduction in any medium, provided the original author(s) and source are credited. 


\section{REFERENCES}

1. National Heart, Lung and Blood Institute. National Asthma Education and Prevention Program Expert Panel III: Guidelines for the diagnosis and management of asthma. US Department of Health and Human Services, ed. Bethesda, MD: National Heart, Lung \& Blood Institute; 2007.

2. Eggleston PA, Malveaux FJ, Butz AM, et al. Medications used by children with asthma living in the inner city. Pediatrics. 1998;101(3 Pt 1):349-354.

3. Ayala GX, Miller D, Zagami E, Riddle C, Willis S, King D. Asthma in middle schools: what students have to say about their asthma. J Sch Health. 2006;76(6):208-214.

4. Divertie V. Strategies to promote medication adherence in children with asthma. MCN Am J Matern Child Nurs. 2002;27(1):10-18.

5. van Es SM, le Coq EM, Brouwer AI, Mesters I, Nagelkerke AF, Colland VT. Adherencerelated behavior in adolescents with asthma: results from focus group interviews. $J$ Asthma. 1998;35(8):637-646.

6. Farber HJ, Capra AM, Finkelstein JA, et al. Misunderstanding of asthma controller medications: association with nonadherence. J Asthma. 2003;40(1):17-25.

7. Magzamen S, Patel B, Davis A, Edelstein J, Tager IB. Kickin' Asthma: school-based asthma education in an urban community. J Sch Health. 2008;78(12):655-665.

8. Christiansen SC, Zuraw BL. Serving the underserved: school-based asthma intervention programs. J Asthma. 2002;39(6):463-472.

9. Anderson ME, Freas MR, Wallace AS, Kempe A, Gelfand EW, Liu AH. Successful schoolbased intervention for inner-city children with persistent asthma. J Asthma. 2004;41 (4):445-453.

10. Bartholomew LK, Sockrider M, Abramson SL, et al. Partners in school asthma management: evaluation of a self-management program for children with asthma. J Sch Health. 2006;76(6):283-290.

11. Berg J, Tichacek MJ, Theodorakis R. Evaluation of an educational program for adolescents with asthma. J Sch Nurs. 2004;20(1):29-35.

12. Bruzzese JM, Bonner S, Vincent EJ, et al. Asthma education: the adolescent experience. Patient Educ Couns. 2004;55(3):396-406.

13. Gerald LB, McClure LA, Harrington KF, et al. Design of the supervised asthma therapy study: implementing an adherence intervention in urban elementary schools. Contemp Clin Trials. 2008;29(2):304-310.

14. Gerald LB, Redden D, Wittich AR, et al. Outcomes for a comprehensive school-based asthma management program. J Sch Health. 2006;76(6):291-296.

15. McCann DC, McWhirter J, Coleman H, Calvert M, Warner JO. A controlled trial of a school-based intervention to improve asthma management. Eur Respir J. 2006;27(5):921928.

16. Millard MW, Johnson PT, McEwen M, et al. A randomized controlled trial using the school for anti-inflammatory therapy in asthma. J Asthma. 2003;40(7):769-776.

17. Velsor-Friedrich B, Pigott TD, Louloudes A. The effects of a school-based intervention on the self-care and health of African-American inner-city children with asthma. J Pediatr Nurs. 2004;19(4):247-256.

18. Yeatts K, Maier W, Shy C. Asthma inhaler use and barriers in a population-based sample of African-American and white adolescents. Ann Allergy Asthma Immunol. 2000;84 (1):94-100.

19. Davis A, Savage Brown A, Edelstein J, Tager IB. Identification and education of adolescents with asthma in an urban school district: results from a large-scale asthma intervention. J Urban Health. 2008;85(3):361-374.

20. Magzamen S, Mortimer KM, Davis A, Tager IB. School-based asthma surveillance: a comparison of student and parental report. Pediatr Allergy Immunol. 2005;16:669-678.

21. Asher MI, Keil U, Anderson HR, et al. International Study of Asthma and Allergies in Childhood (ISAAC): rationale and methods. Eur Respir J. 1995;8:483-491. 
22. Lozano P, Finkelstein JA, Hecht J, Shulruff R, Weiss KB. Asthma medication use and disease burden in children in a primary care population. Arch Pediatr Adolesc Med. 2003;157:81-88.

23. Menckeberg TT, Bouvy ML, Bracke M, et al. Beliefs about medicines predict refill adherence to inhaled corticosteroids. J Psychosom Res. 2007;64:47-54.

24. Halm EA, Mora P, Leventhal H. No symptoms, no asthma: the acute episodic disease belief is associated with poor self management among inner-city adults with persistent asthma. Chest. 2006;129:573-580. 